\title{
Perceived sexual control, sex-related alcohol expectancies and behavior predict substance-related sexual revictimization
}

\author{
Kate Walsh $^{\mathrm{a}, *}$, Terri Messman-Moore ${ }^{\mathrm{b}}$, Noga Zerubavel ${ }^{\mathrm{b}}$, Rachel B. Chandley ${ }^{\mathrm{b}}$, \\ Kathleen A. DeNardi ${ }^{\text {b }}$, Dave P. Walker ${ }^{\text {b }}$ \\ a Department of Epidemiology, Columbia University, USA \\ ${ }^{\mathrm{b}}$ Miami University of Ohio, USA
}

\section{A R T I C L E I N F O}

\section{Article history:}

Received 9 August 2012

Received in revised form

19 November 2012

Accepted 20 November 2012

Available online 9 January 2013

\section{Keywords:}

Child sexual abuse

Substance-facilitated rape

Control

Sex-related alcohol expectancies

Sexual risk behavior

\begin{abstract}
A B S T R A C T
Objectives: Although numerous studies have documented linkages between childhood sexual abuse (CSA) and later sexual revictimization, mechanisms underlying revictimization, particularly assaults occurring in the context of substance use, are not well-understood. Consistent with Traumagenic Dynamics theory, the present study tested a path model positing that lowered perceptions of sexual control resulting from CSA may be associated with increased sex-related alcohol expectancies and heightened likelihood of risky sexual behavior, which in turn, may predict adult substance-related rape.

Methods: Participants were 546 female college students who completed anonymous surveys regarding CSA and adult rape, perceptions of sexual control, sex-related alcohol expectancies, and likelihood of engaging in risky sexual behavior.

Results: The data fit the hypothesized model well and all hypothesized path coefficients were significant and in the expected directions. As expected, sex-related alcohol expectancies and likelihood of risky sexual behavior only predicted substance-related rape, not forcible rape.

Conclusions: Findings suggested that low perceived sexual control stemming from CSA is associated with increased sex-related alcohol expectancies and a higher likelihood of engaging in sexual behavior in the context of alcohol use. In turn these proximal risk factors heighten vulnerability to substance-related rape. Programs which aim to reduce risk for substance-related rape could be improved by addressing expectancies and motivations for risky sexual behavior in the context of substance use. Implications and future directions are discussed.
\end{abstract}

(c) 2012 Elsevier Ltd. All rights reserved.

\section{A model of substance-related sexual revictimization: child sexual abuse, perceived sexual control, sex-related alcohol expectancies and risky sexual behavior as predictors}

Myriad studies have documented linkages between early sexual abuse and later sexual revictimization among women (for review see Classen, Palesh, \& Aggarwal, 2005). However, mechanisms underlying revictimization are not well-understood. Although perpetrators bear complete responsibility for sexual abuse and assault, risk reduction efforts which help women decrease their vulnerability can be greatly informed by understanding processes that may increase risk for sexual revictimization. Traumagenics dynamics theory (Finkelhor \& Browne, 1985) suggests that child sexual abuse (CSA) may significantly impact several key domains of functioning through four key processes: traumatic sexualization, stigmatization, betrayal,

\footnotetext{
* Corresponding author address: Mailman School of Public Health, Columbia University, 722 West 168th Street, New York, NY 10032, USA.
} 
and powerlessness. Traumatic sexualization refers to the development of inappropriate and dysfunctional sexual behaviors as a result of sexual abuse; stigmatization refers to negative connotations about sexual abuse (e.g., shame and guilt) that become part of the child's self-concept; betrayal refers to the process whereby the child learns that someone they depend on to love or care for them has caused them harm; powerlessness refers to the process by which a child's will and self-efficacy are repeatedly undermined or disregarded. Each of these dynamics may contribute to psychological injury as a result of sexual abuse by disrupting the development of normative sexual behaviors and satisfying sexual relationships, increasing perceived stigmatization, diminishing the ability to trust, and engendering feelings of powerlessness and low self-efficacy. These maladaptive manifestations may, in turn, increase risk for adult sexual revictimization. For instance, among women attending an STD clinic, CSA has been shown to be a unique predictor of risky adult sexual behavior after controlling for the experience of other forms of child maltreatment (Senn \& Carey, 2010). Additionally, among college women, risky sexual behavior (e.g., an increased number of consensual sexual partners) has been shown to mediate relations between CSA and later sexual revictimization (Messman-Moore, Walsh, \& DiLillo, 2010; Orcutt, Cooper, \& Garcia, 2005). However, little is known about motivations for risky sexual behavior or the context in which risky sexual behaviors take place.

Traumagenic dynamics theory suggests that powerlessness is a common outcome of CSA (Finkelhor \& Browne, 1985). Thus, one motivation for victims to engage in risky sexual behavior may be to regain perceived control over sexual encounters. Indeed, consistent with traumagenic dynamics theory, CSA victims have been shown to report more traumatic sexualization (including fear of sex, preoccupation with sex, and use of sex to feel powerful or worthwhile), powerlessness, and guilt when compared to women who do not report CSA experiences (Senn, Carey, \& Coury-Doniger, 2011). The maladaptive learning that occurs in the context of child sexual abuse may lead female victims to hold perceptions of the self as damaged, as well as perceptions of low self-efficacy and control in sexual or intimate situations (Noll, Horowitz, Bonanno, Trickett, \& Putnam, 2003). Thus, it is not surprising that CSA victims report a greater number of unprotected sexual encounters, increased sex trading (i.e., trading sex for money, goods, or services), and a greater number of lifetime sexual partners when compared to non-victims (Senn et al., 2011). Although it is plausible that women who have experienced uncontrollable and unpredictable CSA may engage in risky consensual sexual behavior in an attempt to establish control over sexual encounters, these victims also may vacillate between preoccupation with sex and fear of sex such that they seek particular circumstances or contextual factors to make them more comfortable with engaging in sexual behavior. For example, victims are more likely than nonvictims to report using alcohol or drugs to overcome sexual inhibition and increase comfort in sexual situations (Sanjuan, Langenbucher, \& Labouvie, 2009). Further, experimental research indicates that community women high in sexual anxiety are more likely to engage in risky sexual behavior after they have been drinking, and are motivated to use alcohol in order to reduce such fears (Stoner, George, Peters, \& Norris, 2007). Therefore, sexual fears or perceptions of low control in sexual situations may impact CSA victims' use of alcohol in a sexual context.

Although alcohol may decrease fear or inhibitions during sexual encounters, its use in sexual situations can be risky. Among college women, estimates of substance-facilitated sexual assault are high (e.g., McCauley, Ruggiero, Resnick, Conoscenti, \& Kilpatrick, 2009), with almost three-quarters of female college rape victims reporting being intoxicated at the time of their assault (Mohler-Kuo, Dowdall, Koss, \& Wechsler, 2004). Alcohol use and risky sexual behaviors have been shown to mediate associations between adolescent sexual victimization and revictimization during the first year of college among women (Testa, Hoffman, \& Livingston, 2010). However, women's problematic alcohol or drug use does not invariably increase revictimization risk (Messman-Moore \& Long, 2003), suggesting a need for additional studies to examine other factors that may impact this phenomenon, including consensual sexual behavior (Messman-Moore et al., 2010). The relevance of behavioral risk factors such as women's alcohol use may vary depending upon contextual variables in episodes of revictimization, such as level of victim intoxication or incapacitation (Testa, Livingston, VanZile-Tamsen, \& Frone, 2003), which impacts the perpetrator's method of coercion (e.g., the need to use force). In essence, perpetrators may rely on women's inability to resist or defend themselves if they have been drinking heavily prior to a sexual encounter, utilizing her level of intoxication or incapacitation rather than physical force to perpetrate sexual aggression. Thus, research examining risk for revictimization should carefully examine factors that may increase risk for alcohol- or drug-related assaults compared to those assaults involving physical coercion (Testa, 2004).

Research that aims to elucidate motivations for risky consensual sexual behaviors in the context of alcohol use may be a useful next step in developing targeted interventions to reduce revictimization risk. One factor that may increase the likelihood of risky sexual behavior and revictimization in the context of alcohol use are the beliefs or expectancies that victims hold regarding the effects that alcohol will have on sexual experiences. For example, alcohol use has been shown to increase the likelihood of engaging in risky sexual behavior among women who expect that alcohol will enhance sex (Dermen, Cooper, \& Agocha, 1998). Among CSA victims who have developed low perceived sexual control and increased fear of sex, expectancies that alcohol will make sex more enjoyable may increase the likelihood of engaging in risky sexual behavior when using alcohol. Risky sex when using alcohol, in turn, may mediate associations between CSA and adult substance-facilitated rape.

Despite theoretical indications that CSA may increase feelings of powerlessness (Finkelhor \& Browne, 1985) and risky sexual behavior may represent attempts to gain power and control in sexual situations (Monahan, Miller, \& Rothspan, 1997), we are aware of no studies that use these constructs to test a model of risk for adult substance-related sexual assault. Furthermore, increased understanding of the context in which risky sexual behaviors occur is a critical next step in developing more effective interventions that account for intrapersonal, interpersonal, and environmental factors that may contribute to risk for sexual revictimization. Explicating the processes that may contribute to this form of sexual assault can 
aid in identifying intervention targets that can improve sexual risk reduction programs. Thus, our primary aim was to test a path model that included perceived sexual control, sex-related alcohol expectancies, and likelihood of risky sexual behavior when drinking as mediators between CSA and adult substance-facilitated rape. A secondary aim was to clarify the relevance of sex-related alcohol expectancies and risky sexual behavior as proximal predictors of substance-related revictimization rather than forcible revictimization. We predicted that alcohol expectancies and alcohol-facilitated risky sexual behavior in the context of alcohol use will predict substance-related rape but not forcible rape.

\section{Method}

\section{Participants}

Participants were 546 college women reporting a mean age of $18.7(\mathrm{SD}=0.84)$ who completed anonymous surveys for course credit. Because women report more than $90 \%$ of sexual assaults (Pimlott-Kubiak \& Cortina, 2003), we focused exclusively on college women in this study. Eligibility criteria included being 18 and female; there were no exclusion criteria. All female students enrolled in an introductory psychology course over three consecutive semesters (Fall 2007, Spring 2008, Fall 2008) were eligible to participate. Students were required to complete a set number of experimental hours and allowed to choose from numerous studies (or alternate reading assignments), with approximately 780 female students enrolled across these three semesters. Based upon this, the estimated participation rate was approximately 70\% (546/780). Most participants were Caucasian (92.9\%; $n=507)$; however, $2.2 \%(n=12)$ were African-American/Black, $1.5 \%(n=9)$ were Asian, .9\% $(n=5)$ were biracial, .5\% $(n=3)$ were Hispanic/Latina, .2\% $(n=1)$ were Native American, and $1.5 \%(n=9)$ reported their ethnicity as other. The majority of participants were freshman/in their first year of university $(65.2 \% ; n=356), 28.0 \%$ $(n=153)$ were sophomores/in their second year of university, 3.8\% $(n=21)$ were juniors/in their third year of university, and $2.9 \%(n=16)$ were seniors/in their final/fourth year of university. Most participants were unmarried $(95.1 \%$; $n=519)$ and slightly less than half the sample (49.5\%) reported an annual household (parental) income of $\$ 100,000$ or more while growing up.

\section{Measures}

Childhood Trauma Questionnaire (Bernstein E'Fink, 1998). The sexual abuse subscale of the Childhood Trauma Questionnaire (CTQ; Bernstein \& Fink, 1998) is a 5-item subscale containing Likert-type questions designed to screen for child sexual abuse experiences while growing up. To clearly distinguish between child sexual abuse and adolescent/adult sexual assault, instructions were modified to screen for abusive experiences that occurred prior to age 14. Numerous investigations attest to the reliability and validity of scores on this measure (Bernstein, Fink, Handelsman, \& Foote, 1994; Bernstein et al., 2003). The CTQ yields a continuous sexual abuse severity score and a dichotomous sexual abuse score (indicating presence of absence of sexual abuse) that was derived via Receiver Operator Characteristic analyses indicating that individuals who score six or greater on the subscale should be classified as abuse victims (Bernstein \& Fink, 1998). The continuous sexual abuse severity score was used in path analyses, but the dichotomous score was used to present the prevalence of sexual abuse in the current sample. Alpha for the sexual abuse subscale in the present sample was .92.

Modified Sexual Experiences Survey (MSES; Zerubavel \& Messman-Moore, in press). The MSES is an expanded version of the Sexual Experiences Survey (SES; Koss \& Gidycz, 1985) that was used to assess substance-related rape since the age of 14. This measure assesses rape by asking a series of yes/no behaviorally specific questions. Questions regarding alcohol-involved rape were modified and modeled after those used by Muehlenhard, Powch, Phelps, and Giusti, (1992). Substance-related rape was considered to have occurred if a woman responded "yes" to one of the following three questions: (1) "Have you had oral sex (giving a blow job, or going down, but not intercourse) when you didn't want to because you were incapable of giving consent or resisting due to alcohol or drugs?" (2) "Have you had sexual intercourse when you didn't want to because you were incapable of giving consent or resisting due to alcohol or drugs?" (3) "Have you had sex acts (anal intercourse, vaginal or anal penetration by fingers, or objects other than the penis) when you didn't want to because you were incapable of giving consent or resisting due to alcohol or drugs?" Participants who reported oral sex, vaginal or anal intercourse, or vaginal or anal penetration by objects when unable to consent or resist due to the use of alcohol or drugs were considered to have experienced substance-related rape. Participants who reported the same types of unwanted sexual experiences that occurred due to threats or use of force by the perpetrator were considered to have experienced forcible rape.

Risky Sex Scale (O'Hare, 2001). Sex-related alcohol expectancies and risky consensual sexual behavior in the context of alcohol use were assessed using the Sex Expectancies and Likelihood of Risky Sex Behaviors subscales, respectively. A sample sex-related alcohol expectancy item is "I enjoy having sex more if I've had some alcohol" while a sample risky sex behavior is "If I have been drinking or using other substances with a new date, I am more likely to have sex with that person." Coefficient alpha was .93 for the sex-related alcohol expectancies scale and .86 for the risky sexual behaviors scale. These constructs were measured to assess traumatic sexualization in the context of alcohol use.

Perceived Control (Zeanah \& Schwartz, 1996). Perceived control was assessed using the Control subscale of the Sexual Self-Esteem Inventory for Women (SSEI-W) which measures one's ability to direct or manage sexual thoughts, feelings, or interactions. Participants are asked to rate their reactions and feelings about their sexual experiences, by indicating the degree of agreement with each statement on a 6-point Likert scale. Examples of items from this measure include: "I am 
Table 1

Correlations among study variables.

\begin{tabular}{|c|c|c|c|c|c|c|c|}
\hline & $\%(n)$ or $M(\mathrm{SD})$ & CSA & SFR & FR & Control & Sex Exp & Risky Sex \\
\hline CSA & $6.2 \%(n=34)$ & - & $.09^{*}$ & $.14^{* *}$ & $-.18^{* *}$ & .04 & .08 \\
\hline SFR & $19.4 \%(n=103)$ & & - & $.17^{* *}$ & $-.22^{* *}$ & $.19^{* *}$ & $.23^{* *}$ \\
\hline FR & $6.4 \%(n=35)$ & & & - & $-.14^{* *}$ & .07 & $.09^{*}$ \\
\hline Control & $31.2(\mathrm{SD}=7.1)$ & & & & - & $-.31^{* *}$ & $-.36^{* *}$ \\
\hline Sex Exp & $18.1(\mathrm{SD}=6.5)$ & & & & & - & $.38^{* *}$ \\
\hline Risky Sex & $10.3(\mathrm{SD}=4.7)$ & & & & & & - \\
\hline
\end{tabular}

Note: CSA, child sexual abuse; SFR, substance-related rape; FR, forcible rape; Control, perceived sexual control; Sex Exp, sex-related alcohol expectancies; Risky Sex, likelihood of engaging in risky sexual behavior.

${ }^{*} p<05$.

** $p<.01$.

$* * * p<.001$.

afraid of losing control sexually," "I worry that I won't be able to stop something I don't want to do in a sexual situation," and "In a sexual situation, I know what I want but don't know how to get it." This subscale consists of 16 items and had an internal consistency alpha in the present sample of .92. This construct was measured to assess powerlessness in sexual situations.

Procedures

All procedures and materials for the study were approved by the second author's institutional review board for human subjects in research. Data for the current study were collected across three semesters, and all students in the introductory psychology course had access to Experimetrix, an online tool that advertised the study for course credit and allowed interested participants to sign up for a study session. Following informed consent, participants completed anonymous questionnaires (as well as a set of other questionnaires not pertinent to the present study) in a single group session approximately 60-90 min in duration. Participants completed questionnaires in groups of 7-50 with ample space (at least one seat) between participants to ensure privacy and anonymity. All research sessions were staffed exclusively by female research assistants. Upon completion of the study, participants were debriefed and provided with the researchers' contact information and contact information for campus and community mental health professionals.

\section{Statistical analyses}

Analyses included two steps. First, descriptive information and correlations between study variables were presented. Second, path modeling procedures categorizing the dependent variables (substance-related and forcible rape) as dichotomous outcomes were employed. The model included one exogenous (CSA) and five endogenous variables (perceived sexual control, likelihood of sexual behavior while drinking/drunk, sex-related alcohol expectancies). Missing data were minimal, ranging from $0 \%$ for adult sexual assault to $5.7 \%$ for perceived control. Missing data were handled via Maximum Likelihood estimation with robust standard errors (MLR), a procedure that is asymptotically equivalent to Multiple Imputation (MI) (Graham, Olchowski, \& Gilreath, 2007).

\section{Results}

Descriptive information and correlations among the study variables are presented in Table 1 . Approximately $6.2 \%(n=34)$ of participants reported CSA, $19.4 \%(n=106)$ reported at least one substance-related rape since age 14 , and $6.4 \%(n=35)$ reported forcible rape. Approximately $32.1 \%$ of CSA victims and $19.1 \%$ of CSA non-victims reported substance-related rape since age $14 ; 21.4 \%$ of CSA victims and $5.8 \%$ of CSA non-victims reported forcible rape since age 14 . Although substancerelated rape was the primary dependent variable of interest, a respondent could have experienced both substance-related and forcible rape. In our sample, these types of rape were correlated at $.17(p<.001)$, and $15.1 \%(n=16)$ of substance-related rape victims also reported a forcible rape. To account for the co-occurrence of both types of rape, forcible rape was included as a second, correlated outcome in the path model. Treating the data in this manner allowed us to predict different types of rape experiences, rather than different types of victims.

Bivariate associations between study variables emerged in the expected direction such that victimization experiences were negatively associated with perceived sexual control, and sex-related alcohol expectancies and risky sexual behavior were positively associated with adult substance-facilitated rape. Fig. 1 depicts the results from the hypothesized path model specifying relationships between CSA, perceived sexual control, sex-related alcohol expectancies, likelihood of sexual behavior while drinking/drunk, substance-facilitated rape, and forcible rape. The model included one exogenous variable, CSA, and five endogenous variables: perceived sexual control, sex-related alcohol expectancies, sexual behavior while drinking/drunk, adult substance-facilitated rape and adult forcible rape. Model fit was evaluated using Kline (2005) recommendation that the model chi-square statistic be non-significant and $\mathrm{Hu}$ and Bentler (1999) recommendations that the Comparative Fit Index (CFI) be greater than .95, the Root Mean Square Error of Approximation (RMSEA) be less than or equal to .06, and the 


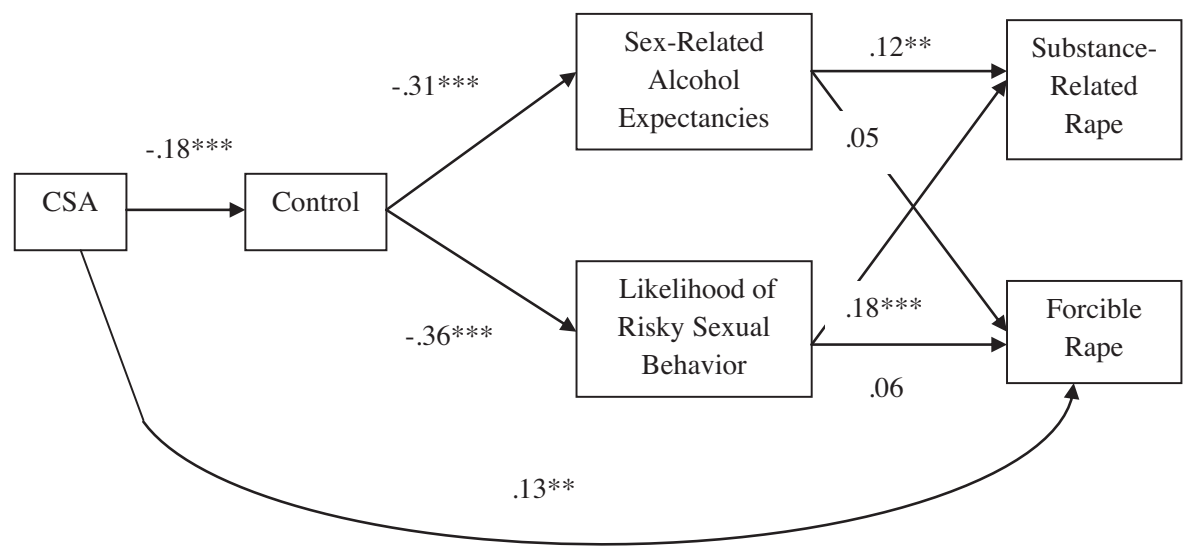

Fig. 1. Path model predicting substance-related and forcible rape.

Standardized Root Mean Square Residual (SRMR) be less than .08 . The model was a good fit for these data, $\chi^{2}(4)=7.8, p=.06$; $\mathrm{CFI}=.98$; RMSEA $=0.05$; SRMR $=0.03$, and all path coefficients were in the expected direction. The previously significant link between CSA and adult substance-facilitated rape (path coefficient $=.09, p<.05$ ) was reduced to non-significance (path coefficient $=.07, p=.10$ ) in the presence of the hypothesized mediators, suggesting that the present model fully mediates the CSA-adult substance-facilitated rape link. However, neither sex-related alcohol expectancies nor sexual behavior while drinking/drunk were associated with forcible rape, and the significant relationship between CSA and forcible rape remained significant in the presence of the mediators ( path coefficient $=.13, p<.01$ ).

\section{Discussion}

Although a substantial body of literature highlights strong linkages between CSA and adult sexual revictimization (see Classen et al., 2005 for review), less information is available regarding the intrapersonal factors and contexts in which these victimizations occur. Thus, the present study examined a model of risk for substance-related rape that included CSA, perceived sexual control, sex-related alcohol expectancies, and likelihood of sexual behavior in the context of drinking as predictors. Nearly $20 \%$ of participants reported substance-facilitated rape, corroborating recent research suggesting that this form of adult victimization is common among college women (McCauley et al., 2009). However, only 6.5\% of participants reported a history of CSA, which is lower than the prevalence reported in many other studies of college students but consistent with the prevalence reported in other studies at this university (Messman-Moore et al., 2010). The model fit the data well and findings suggested that low perceived control may be a distal mediator of the link between CSA and substance-facilitated sexual revictimization that operates through sex-related alcohol expectancies and sexual behavior while drinking/drunk. More specifically, CSA victims who develop feelings of powerlessness as a result of unpredictable and uncontrollable abuse experiences may attempt to feel more in control of their sexuality by engaging in consensual sexual behavior when using substances. Discomfort or fear of sex may encourage these women to engage in alcohol use prior to sex, particularly if they hold beliefs that sexual encounters will be enhanced or their inhibitions diminished by the use of alcohol. Alcohol use and sexual behavior when using alcohol have both been associated with increased risk for unwanted sexual experiences (Cashell-Smith, Connor, \& Kypri, 2007) and sexual assault (Testa et al., 2010) more specifically.

These results suggest that women-particularly CSA victims-who are concerned about their abilities to effectively negotiate sexual situations might use alcohol in this context because they believe alcohol will enhance their sexual experience. However, given the relationships found here, it is likely that victims use alcohol to compensate for their sense of powerlessness in sexual situations. These findings fit with the notion that alcohol may serve as "liquid courage" for a woman who feels she lacks control in sexual situations but is motivated to engage in sexual behavior for various reasons (Phillips, 2000). Young women who have been drinking are more likely to be focused on the short-term benefits of sexual behavior and ignore or overlook the potential for harm and long-term negative consequences (Griffin, Umstattd, \& Usdan, 2010). If a woman does not experience negative consequences the first time she engages in risky, alcohol-facilitated sexual behavior, she may continue to use alcohol to increase perceived sexual control, setting up a dangerous trajectory that increases risk for sexual victimization. Furthermore, women often do not label unwanted sexual experiences as rape or sexual assault if they have been consuming alcohol prior to the assault, as they may blame themselves for the experience or assume that they wanted it, particularly if they are reporting sexual ambivalence (Peterson \& Muehlenhard, 2004). Not labeling such incapacitated rape as "rape" can be a way to re-establish a sense of control and agency in sexual situations by permitting victims to believe that they had more power and control in the situation than they truly did. Unfortunately, current research indicates that experiencing substance-facilitated rape is associated with considerable psychological distress (Brown, Testa, \& Messman-Moore, 2009), and even if it is not labeled as "rape," victims may experience long-term negative consequences (Harned, 2004). 
A secondary aim of the study was to examine whether the model under investigation predicted forcible revictimization as well as substance-related revictimization. As hypothesized, forcible rape was not related to sex-related alcohol expectancies or risky sexual behavior when intoxicated. This lends further support for earlier research suggesting that risk factors for these two different forms of sexual assault may differ (Testa et al., 2003), and that particular aspects of sexual behavior (i.e., in the context of drinking) may be more powerful proximal predictors of substance-related rather than forcible revictimization. Findings here are consistent with Messman-Moore and Long (2003), who suggest that risk for sexual revictimization is multiply determined. The multiple pathways leading from CSA to revictimization may reflect differential risk factors relevant to different types of sexual aggression, as well as individual proclivities towards particular aspects of risky or vulnerabilityenhancing behavior (i.e., likelihood of engaging in sex while intoxicated versus dissociation). Future studies should continue to examine multiple, specific pathways leading from CSA to different forms of sexual revictimization.

Although findings from the current study extend our understanding of risk for different types of sexual revictimization, they should be considered in the context of limitations. Although the hypothesized model was supported in the present study, data were cross-sectional which precludes definitive statements about the temporal ordering of the study variables. Longitudinal studies are needed to draw more definitive conclusions regarding relations among these variables. Although substance-facilitated sexual assault and revictimization are substantial problems for college women, these findings should be replicated across community and clinical samples to determine whether the patterns observed among relatively high-functioning college women generalize to other populations. Generalizability is further limited by the predominantly Caucasian and upper-middle class sample; therefore, additional studies are needed to determine whether perceived sexual control, sex-related alcohol expectancies, and risky sexual behaviors serve as mechanisms for revictimization among more ethnically and economically diverse samples. Similarly, a small proportion of women in the current sample reported CSA. The current study used the CTQ, a well-validated and widely used screening instrument for CSA, but assessed sexual abuse experiences occurring prior to age 14 because studies are increasingly showing that child and adolescent sexual abuse may differ substantively in context and risk factors. Other studies often collapse child and adolescent sexual abuse and assess the prevalence of sexual abuse prior to age 18 . As indicated by a recent meta-analysis of international child sexual abuse rates (Stoltenborgh, van IJzendoorn, Euser, \& Bakermans-Kranenburg, 2011), sexual abuse prevalence increases from $~ 6 \%$ prior to age 14 to peak at nearly $30 \%$ at age 14 and it hovers near $17-18 \%$ from ages $15-18$. Thus, it is possible that the low prevalence observed here could be attributed to the measurement of sexual abuse during this earlier developmental period. Nonetheless, it is important to examine whether relationships observed here extend to other college samples with potentially higher prevalence of CSA. Additionally, although more than $90 \%$ of sexual assaults are reported by women (Pimlott-Kubiak \& Cortina, 2003), men also experience rape; thus, there is a need for research focused on the correlates and processes that increase risk for rape among men, including those in college.

Despite these limitations, the present findings identify important targets for intervention and risk reduction among CSA victims. Consistent with previous studies (e.g., Marx, Nichols-Anderson, Messman-Moore, Miranda, \& Porter, 2000; Messman-Moore et al., 2010), our findings highlight the importance of alcohol-facilitated sexual behavior and sex-related alcohol expectancies in increasing such risk. More importantly, the present study indicates that alcohol expectancies, highrisk sexual behavior and sexual revictimization cannot be treated as separate entities in education and prevention programs. Risks associated with alcohol use and sexual behavior must be incorporated into both sexual assault prevention and alcohol awareness education (Kaly, Heesacker, \& Frost, 2002). Merely dispelling the dangers of drinking at new student orientation will not address concerns related to sexuality and sexual control.

Ultimately, interventions aimed at female adolescents and young women may be more effective if such programs focus on issues pertaining to struggles with sexual desire, control and communication. Helping victims to better understand motivations for engaging in sexual behavior when drinking/drunk as well as outcomes that may result may be important psycho-educational components that current risk-reduction programs overlook. Further, helping CSA victims to identify alternative means of regaining a sense of power and control in sexual relationships may be an important avenue for future interventions. Increasing sexual control, as well as addressing sex-related alcohol-expectancies, may benefit women by reducing rates of risky sexual behavior and consequently, risk for substance-related rape and revictimization.

\section{Acknowledgements}

The authors would like to acknowledge numerous individuals who assisted with data collection, including Alison Kaiser, Erika Kelley, Emily Prather, Melissa Roemmele, Misti Rogers, Emily Lambrecht, Rachel Chait, Kristi Wolfe, Ashley Newlove, Sarah Griffeth and Kate Rosenblatt.

\section{References}

Bernstein, D. P., \& Fink, L. (1998). Childhood Trauma Questionnaire: A retrospective self-report questionnaire and manual. San Antonio, TX: The Psychological Corporation.

Bernstein, D. P., Fink, L., Handelsman, L., \& Foote, J. (1994). Initial reliability and validity of a new retrospective measure of child abuse and neglect. American Journal of Psychiatry, 151, 1132-1136.

Bernstein, D. P., Stein, J. A., Newcomb, M. D., Walker, E., Pogge, D., Ahluvalia, T., et al. (2003). Development and validation of a brief screening version of the Childhood Trauma Questionnaire. Child Abuse and Neglect, 27, 169-190. 
Brown, A. L., Testa, M., \& Messman-Moore, T. L. (2009). Psychological consequences of sexual victimization due to different methods of coercion. Violence Against Women, 15, 898-919.

Cashell-Smith, M. L., Connor, J. L., \& Kypri, K. (2007). Harmful effects of alcohol on sexual behavior in a New Zealand university community. Drug and Alcohol Review, 26, 645-651.

Classen, C. C., Palesh, O. G., \& Aggarwal, R. (2005). Sexual revictimization: A review of the empirical literature. Trauma, Violence and Abuse, 6, 103-129.

Dermen, K. H., Cooper, M. L., \& Agocha, V. B. (1998). Sex-related alcohol expectancies as moderators of the relationship between alcohol use and risky sex in adolescents. Journal of Studies on Alcohol, 59, 71-77.

Finkelhor, D., \& Browne, A. (1985). The traumatic impact of child sexual abuse: A conceptualization. American Journal of Orthopsychiatry, 55, 530-541.

Graham, J. W., Olchowski, A. E., \& Gilreath, T. D. (2007). How many imputations are really needed? Some practical clarifications of multiple imputation theory. Prevention Science, 8, 206-213.

Griffin, J. A., Umstattd, M. R., \& Usdan, S. L. (2010). Alcohol use and high-risk sexual behavior among collegiate women: A review of research on Alcohol Myopia Theory. Journal of American College Health, 58, 523-532.

Harned, M. S. (2004). Does it matter what you call it? The relationship between labeling unwanted sexual experiences and distress. Journal of Consulting and Clinical Psychology, 72(6), 1090-1099.

Hu, L. T., \& Bentler, P. M. (1999). Cutoff criteria for fit indices in covariance structure analysis: Conventional criteria versus new alternatives. Structural Equation Modeling, 6, 1-55.

Kaly, P. W., Heesacker, M., \& Frost, H. M. (2002). Collegiate alcohol use and high-risk sexual behavior: A literature review. Journal of College Student Development, 43(6), 838-850.

Kline, R. B. (2005). Principles and practice of structural equation modeling (2nd ed.). New York, NY: The Guilford Press.

Koss, M. P., \& Gidycz, C. A. (1985). Sexual experiences survey: Reliability and validity. Journal of Consulting and Clinical Psychology, $53,422-423$.

Marx, B. P., Nichols-Anderson, C., Messman-Moore, T., Miranda, R., \& Porter, C. (2000). Alcohol consumption, outcome expectancies, and victimization status among female college students. Journal of Applied Social Psychology, 30(5), 1056-1070.

McCauley, J., Ruggiero, K. J., Resnick, H. S., Conoscenti, L. M., \& Kilpatrick, D. G. (2009). Forcible, drug-facilitated, and incapacitated rape in relation to substance abuse problems: Results from a national sample of college women. Addictive Behaviors, 34, 458-462.

Messman-Moore, T. L., \& Long, P. J. (2003). The role of childhood sexual abuse sequelae in the sexual revictimization of women: An empirical review and theoretical reformulation. Clinical Psychology Review, 23, 537-571.

Messman-Moore, T. L., Walsh, K., \& DiLillo, D. (2010). Emotion dysregulation and risky sexual behavior in revictimization. Child Abuse and Neglect, 34, 967-997.

Mohler-Kuo, M., Dowdall, G. W., Koss, M. P., \& Wechsler, H. (2004). Correlates of rape while intoxicated in a national sample of college women. Journal of Studies on Alcohol, 65, 37-45.

Monahan, J. L., Miller, L. C., \& Rothspan, S. (1997). Power and intimacy: On the dynamics of risky sex. Health Communications, 9, 303-321.

Muehlenhard, C. L., Powch, I. G., Phelps, J. L., \& Giusti, L. M. (1992). Definitions of rape: Scientific and political implications. Journal of Social Issues, $48,23-44$.

Noll, J. G., Horowitz, L. A., Bonanno, G. A., Trickett, P. K., \& Putnam, F. W. (2003). Revictimization and self-harm in females who experienced childhood sexual abuse: Results from a prospective study. Journal of Interpersonal Violence, 18, 1452-1471.

O'Hare, T. (2001). Substance abuse and risky sex in young people: The development and validation of the risky sex scale. The Journal of Primary Prevention, $22,89-101$.

Orcutt, H. K., Cooper, M. L., \& Garcia, M. (2005). Use of sexual intercourse to reduce negative affect as a prospective mediator of sexual revictimization. Journal of Traumatic Stress, 18, 729-739.

Peterson, Z. D., \& Muehlenhard, C. L. (2004). Was it rape? The function of women's rape myth acceptance and definitions of sex in labeling their own experiences. Sex Roles, 51(3/4), 129-144.

Phillips, L. M. (2000). Flirting with danger: Young women's reflections on sexuality and domination. New York: New York University Press.

Pimlott-Kubiak, S., \& Cortina, L. M. (2003). Gender, victimization, and outcomes: Reconceptualizing risk. Journal of Consulting and Clinical Psychology, 71, 528-539.

Sanjuan, P. M., Langenbucher, J. W., \& Labouvie, E. (2009). The role of sexual assault and sexual dysfunction in alcohol/other drug use disorder. Alcoholism Treatment Quarterly, 27, 150-163.

Senn, T. E., \& Carey, M. P. (2010). Child maltreatment and women's adult sexual risk behavior: Childhood sexual abuse as a unique risk factor. Child Maltreatment, 15, 324-335.

Senn, T. E., Carey, M. P., \& Coury-Doniger, P. (2011). Self-defining as sexually abused and adult sexual risk behavior: Results from a cross-sectional survey of women attending an STD clinic. Child Abuse and Neglect, 35, 353-362.

Stoltenborgh, M., van IJzendoorn, M. H., Euser, E. M., \& Bakermans-Kranenburg, M. J. (2011). A global perspective on child sexual abuse: Meta-analysis of prevalence around the world. Child Maltreatment, 16(2), 79-101.

Stoner, S. A., George, W. H., Peters, L. M., \& Norris, J. (2007). Liquid courage: Alcohol fosters risky sexual decision-making in individuals with sexual fears. AIDS \& Behavior, 11, 227-237.

Testa, M. (2004). The role of substance use in male-to-female physical and sexual violence: A brief review and recommendations for future research. Journal of Interpersonal Violence, 19, 1494-1505.

Testa, M., Hoffman, J. H., \& Livingston, J. A. (2010). Alcohol and sexual risk behaviors as mediators of the sexual victimization-revictimization relationship. Journal of Consulting and Clinical Psychology, 78, 249-259.

Testa, M., Livingston, J. A., VanZile-Tamsen, C., \& Frone, M. R. (2003). The role of women's substance use in vulnerability to forcible and incapacitated rape. Journal of Studies on Alcohol, 64, 756-764.

Zeanah, P. D., \& Schwartz, J. C. (1996). Reliability and validity of the sexual self-esteem inventory for women. Assessment, 3(1), 1-15.

Zerubavel, N., \& Messman-Moore, T. L. Sexual victimization, fear of sexual powerlessness, and cognitive emotion dysregulation as barriers to sexual assertiveness in college women. Violence Against Women, in press. 